\title{
Air Pollution and the School Air Environment
}

\author{
P. Fsadni ${ }^{1,2, *}$, and S. Montefort ${ }^{1,2}$ \\ ${ }^{1}$ Department of Medicine, Mater Dei Hospital, Malta and ${ }^{2}$ Faculty of Medicine and Surgery, University of \\ Malta, Msida MSD 2080, Malta
}

\begin{abstract}
There is growing concern about the association of school indoor air quality (SIAQ) with asthma, rhinitis, and rhinoconjunctivitis. Students and school staff deserve the highest standards of school air quality to ensure a safe and productive environment for our children's education. Existing studies highlight the presence of several air pollutants present within school classrooms that have a direct association with poor health and poor student performance. Very little data exist about school air quality in subtropical countries, including the small island nation of Malta. The most commonly identified pollutants include $\mathrm{CO}_{2}, \mathrm{CO}$, volatile organic compounds (VOC), formaldehyde, $\mathrm{O}_{3}, \mathrm{NO}_{2}$, and particulate matter $\left(\mathrm{PM}_{10}, \mathrm{PM}_{2.5}\right)$. These compounds have been associated with an increased risk of asthma and rhinitis in atopic pupils after correcting for alternative exposures. Air quality improvement is an essential measure to help prevent respiratory atopic disease in school occupants. The absence of a European SIAQ monitoring program highlights the urgent need for more research in this field in order to issue the necessary evidence-based recommendations specific to each individual country.
\end{abstract}

Keywords: School, air pollution, asthma, rhinitis, air quality.

\section{INTRODUCTION}

Children's developing body systems are prone to damage from environmental irritants [1,2]. The absence of natural body defenses in children enables airborne toxins to harm the body at low concentrations because children breathe a large volume of air relative to their body weight when compared to adults [2]. Furthermore, children are potentially exposed to a wider variety of pollutants because they are naturally physically active and spend most of their time outside the home in the school environment.

Asthma prevalence, especially among children, has increased in most countries in the past decades with environmental pollution being increasingly recognized as a major trigger of atopy $[3,4]$. Indoor air pollution is particularly important due to the identification of several indoor pollutants, exposure duration, and school building design. Poor school indoor air quality (SIAQ) may have a negative impact on children's health, growth, and performance at school.

The primary aim of this review is to analyze the current knowledge about school indoor air pollutants with particular emphasis on studies carried

"Address correspondence to Peter Fsadni, Faculty of Medicine and Surgery, University of Malta Medical School, Msida MSD 2080, Malta; Tel: +356 79091642; E-mail: peter.fsadni@um.edu.mt out in small island nations such as Malta due to their unique environmental characteristics. The study also aims to focus on the effect indoor air pollutants have on the children's respiratory health. Need and significance of further research will be determined.

\section{METHOD}

This review was conducted by examining articles listed by online bibliographic databases, web reports, and expert opinions. The concept words used in our search were indoor, chemical, pollutants, primary school, small countries, islands, asthma, allergic rhinitis, and atopic eczema. Searches were performed using the individual concept words and completed using all concept words with the word 'AND' between them. The bibliographic databases where PubMed, Embase, Medline, and Web of Science. The practical screening criteria used in our search included looking at studies on SIAQ published between 1987 and 2014, studies performed in primary schools, and manuscripts written in English and Italian were reviewed. Methodological screening criteria were utilized to include studies that had reliable and valid data sources, appropriate analytical methods, and robust and significant statistical analyses. Any studies that did not conform with these practical and methodological criteria were excluded. 
The pollutants identified as the reason for poor indoor and outdoor school air quality in the primary school environment are listed in Figure 1.

Most cross-sectional studies investigated the impact these pollutants had on respiratory health outcomes such as asthma, anti-asthma medication usage, and upper airway symptoms. The studies were carried out in Europe, the USA, and Asia, and no studies were found looking at school pollution and health problems in small island nations. A minority of studies focused on the impact of chemical pollutants on exhaled nitric oxide, lung function, and nasal patency [5-9].

The Health Effects of School Environment (HESE) Study conducted in 5 European countries found a mean carbon dioxide $\left(\mathrm{CO}_{2}\right)$ concentration of 1490 ppm in schools. Scandinavian schools had significantly lower levels [8]. Direct reading instruments were used in all studies, but duration of measurement of $\mathrm{CO}_{2}$ levels within the individual studies ranged from one hour to one week $[10,11]$. Simoni et al. found a direct association between nocturnal cough and upper airway symptoms and $\mathrm{CO}_{2}$ levels [8].

Children in Shanghai had an increased risk of wheezing if exposed to excessive $\mathrm{CO}_{2}$ levels [12]. Mendell et al. reviewed the association between indoor air quality and student performance [13]. Excessive indoor $\mathrm{CO}_{2}$ concentrations were associated with lower scores on a computerized test of reaction time.
A study carried out in Brazilian schools described a mean carbon monoxide (CO) indoor level of 3 ppm [14]. CO exposure in French schools was associated with asthma and atopic eczema in children [15].

A four-year longitudinal study in Swedish primary schools produced a median concentration of 130 $\mu \mathrm{g} / \mathrm{m}^{2}$ for indoor volatile organic compounds (VOC) [16]. Two other studies have shown a mean VOC indoor concentration ranging from 26 to $88 \mu \mathrm{g} / \mathrm{m}^{3}$. Sampling times for VOC using charcoal sorbent tubes ranged from 2 to 4 hours $[16,17]$.

Several studies have linked VOC to atopy. Smedje et al. reported a positive association between current wheezing and a rise of $10 \mu \mathrm{g} / \mathrm{m}^{3}$ in the indoor VOC concentrations in schools [17]. The 6 Cities Study showed that exposure to high concentrations of aldehydes was associated with an increase in exhaled nitric oxide (FeNO) in both asthmatic and non-asthmatic children [5]. A significant association between total school indoor concentrations of VOCs and ocular irritation was also noted [5].

Annesi-Maesano et al. found that formaldehyde $(\mathrm{HCHO})$ concentrations in French primary schools ranged from 12 to $56 \mu \mathrm{g} / \mathrm{m}^{3}$ with a mean concentration of $23 \mu \mathrm{g} / \mathrm{m}^{3}$ [18]. Lower mean concentrations of $\mathrm{HCHO}$ were observed in other published studies ranging between 7 and $9 \mu \mathrm{g} / \mathrm{m}^{3}[12,19,20]$. A study carried out in Australian schools showed

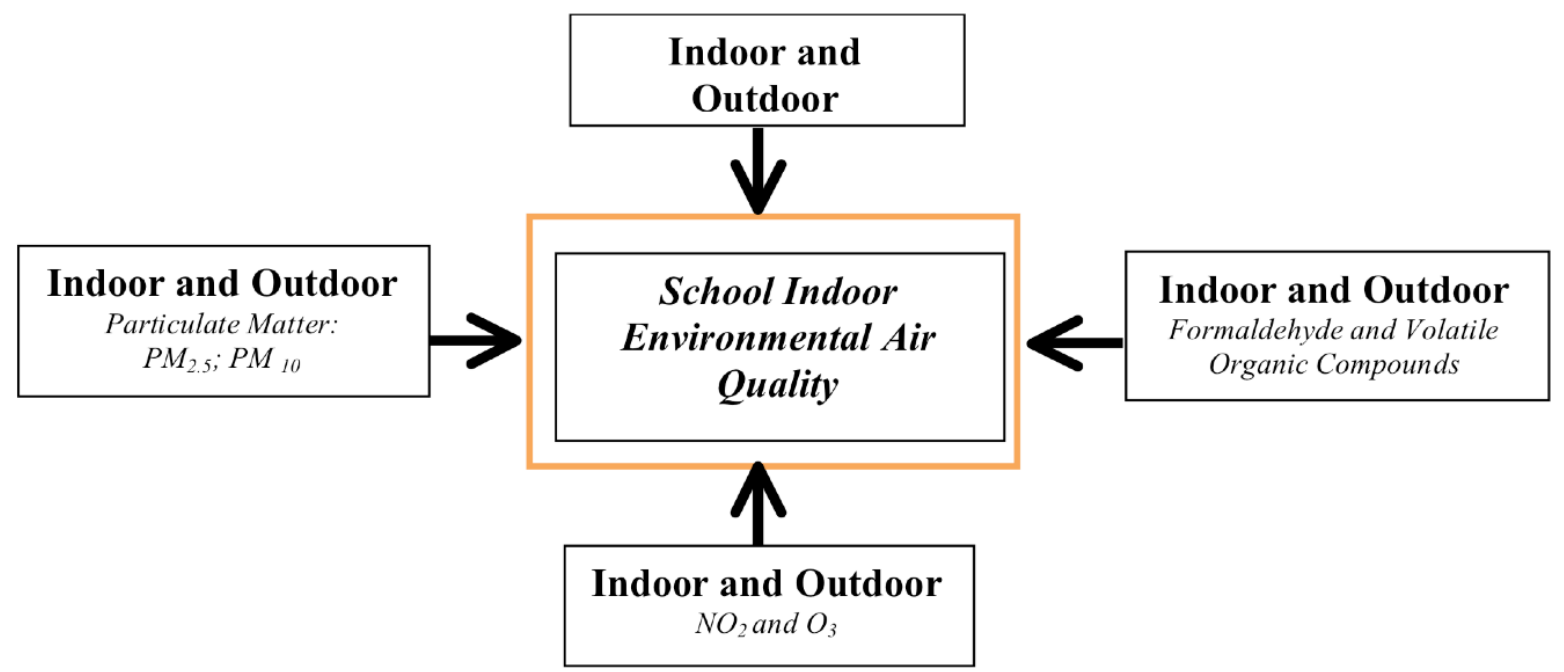

Figure 1. Chemical air pollution in primary schools. 
significantly higher $\mathrm{HCHO}$ indoor concentrations (mean concentration of $35.13 \mu \mathrm{g} / \mathrm{m}^{3}$ ) [21]. The two most commonly utilized $\mathrm{HCHO}$ detection methods were pump-driven glass-fiber filters and the passive filter methods [10,18-23]. Exposure time varied from two to five days $[18,21]$.

Norback et al. described a significant association between higher concentrations of $\mathrm{HCHO}$ and nasal patency [23]. Upper airway inflammation, secondary to $\mathrm{HCHO}$ exposure, was investigated in the 6 Cities Study where children exposed to higher levels of $\mathrm{HCHO}$ had a higher risk of developing allergic rhinitis [18]. HCHO exposure has also been implicated in cumulative wheezing and newly diagnosed asthma among children [10,20].

Air quality analyses in Chinese schools showed significantly higher outdoor concentrations of ozone $\left(\mathrm{O}_{3}\right)$ when compared to indoor levels of the pollutant $\left(20.9\right.$ vs. $\left.5.3 \mu \mathrm{g} / \mathrm{m}^{3}\right)$ [12]. These findings contrast with other studies where no significant differences were seen between indoor and outdoor levels of $\left(\mathrm{O}_{3}\right)$ [10]. Two studies recorded only indoor $\left(\mathrm{O}_{3}\right)$ concentrations with levels of 81.08 and $120 \mu \mathrm{g} / \mathrm{m}^{3}[7,14]$. These findings were significantly higher than the recommended WHO shortterm exposure threshold of $20 \mu \mathrm{g} / \mathrm{m}^{3}$ [24]. Several techniques have been utilized for $\left(\mathrm{O}_{3}\right)$ determinations, including passive diffusion samplers with a seven-day exposure duration, an ultra-violet absorption technique, and chemiluminescence $[7,10,12,25]$.

Conflicting results were published regarding the association between $\left(\mathrm{O}_{3}\right)$ exposure and the health of school children. Two studies described the protective effect of $\left(\mathrm{O}_{3}\right)$ on breathlessness symptomatology and lung function [12,14]. Chen et al. showed a decrease in pulmonary function at peak hourly $\mathrm{O}_{3}$ concentrations greater than $80 \mathrm{ppb}(160$ $\mu \mathrm{g} / \mathrm{m}^{3}$ ) [26]. Children participating in the same study had a lung function decline of $1 \mathrm{~mL} / \mathrm{ppb}$ for peak hourly $\mathrm{O}_{3}$ exposures. $\mathrm{O}_{3}$ exposure in schools has also been associated with an increase in nocturnal symptoms of breathlessness [10]. Romieu et al. found that Mexican school children exposed for two consecutive days to high $\mathrm{O}_{3}$ levels ( $>$ or $=$ $0.13 \mathrm{ppm}$ ) had significantly higher respiratoryrelated school absenteeism periods [27].
Although several studies have focused on nitrogen dioxide $\left(\mathrm{NO}_{2}\right)$ within schools, no significant difference between outdoor and indoor concentrations were found [4]. Smedje et al. reported a mean indoor $\mathrm{NO}_{2}$ level of $5 \mu \mathrm{g} / \mathrm{m}^{3}$ while Brazilian schools were found to have a mean indoor level of $92.5 \mu \mathrm{g} / \mathrm{m}^{3}[14,17]$. The outdoor mean concentration of $\mathrm{NO}_{2}$ in French school yards was $19 \mu \mathrm{g} / \mathrm{m}^{3}$ contrasted with a Shanghai study where the mean $\mathrm{NO}_{2}$ outdoor level was $63 \mu \mathrm{g} / \mathrm{m}^{3}[12,18]$. Passive diffusion samplers were most commonly used for the assessment of $\mathrm{NO}_{2}$ levels in schools $[10,12,17,18,21,23,28]$. Some studies utilized chemiluminescence as an alternative method $[7,26]$.

$\mathrm{NO}_{2}$ has been associated with respiratory disease and skin atopy. Annesi-Maesano et al. reported a significant association between high $\mathrm{NO}_{2}$ exposures and atopic dermatitis in French schools [18]. Furthermore, $\mathrm{NO}_{2}$ levels within the classroom environment were associated with an increased risk of current wheezing and use of anti-asthma medication $[12,18]$.

For every $10 \mu \mathrm{g} / \mathrm{m}^{3}$ increase in $\mathrm{NO}_{2}$, a significant deterioration in mean peak flow rate was observed [14]. Mendell et al. reviewed $\mathrm{NO}_{2}$ based studies and presented persuasive evidence linking school absenteeism and high $\mathrm{NO}_{2}$ exposure [13]. More well-designed studies are needed to analyze the negative health impact of $\mathrm{NO}_{2}$ exposure in children.

Wide variations in particulate matter have been reported. Particulate matter with a 50\% cut-off aerodynamic diameter of $10 \mu \mathrm{m}\left(\mathrm{PM}_{10}\right)$ is commonly used for comparisons. $\mathrm{PM}_{10}$ indoor levels reported by Simoni et al. in Scandinavian schools ranged from $33 \mu \mathrm{g} / \mathrm{m}^{3}$ in Sweden to $169 \mu \mathrm{g} / \mathrm{m}^{3}$ in Denmark [8]. A South American study found a mean school indoor $\mathrm{PM}_{10}$ level of $80 \mu \mathrm{g} / \mathrm{m}^{3}$ [14]. Outdoor $\mathrm{PM}_{10}$ levels in the school environment have been consistently lower than the corresponding indoor levels as seen in the SEARCH study where the mean outdoor $\mathrm{PM}_{10}$ concentration in Italian and Eastern European schools ranged between $44 \mu \mathrm{g} / \mathrm{m}^{3}$ and $50 \mu \mathrm{g} / \mathrm{m}^{3}$ [29].

The main methods used to determine $\mathrm{PM}_{10}$ levels were pump-driven gravimetric samplers, light scat- 
tering dust track monitors, outdoor background monitoring stations, and portable monitors $[8,9,14,30]$. Depending on the methodology used, monitoring duration varied from one hour to four days $[8,29,30]$.

Several studies have confirmed a link between $\mathrm{PM}_{10}$ exposure and upper and lower airway disease. The School Environment and Respiratory Health of Children (SEARCH) initiative reported an increase in nocturnal cough in children exposed to high concentrations of $\mathrm{PM}_{10}$ [29]. Milligan et al. reported an increase in respiratory symptoms in children exposed to high levels of airborne dust in Liverpool, England [31]. A decrease in forced expiratory volume in 1 second $\left(F E V_{1}\right)$ and increased acidity in exhaled breath condensate was seen in asthmatic children exposed to increasing levels of $\mathrm{PM}_{10}$ [9]. High outdoor $\mathrm{PM}_{10}$ levels have also been associated with respiratory morbidity mainly manifesting itself as decreased FEV $_{1}$ and forced vital capacity [7,14]. A study conducted in Taiwan did not show any association between $\mathrm{PM}_{10}$ and the children's respiratory health, but the short-term follow-up methodology used could have been a limiting factor.

The studies we reviewed described levels of indoor particulate matter having a diameter of 2.5 micrometers or less $\left(\mathrm{PM}_{2.5}\right)$ in schools below the recommended WHO threshold for short-term exposure $(200 \mu \mathrm{g} / \mathrm{m} 3)[18,24,25]$. Zuraimi et al. described indoor $\mathrm{PM}_{2.5}$ levels in childcare centers in Singapore ranging from $48.1 \mu \mathrm{g} / \mathrm{m}^{3}$ in centers having mechanical ventilation to $71 \mu \mathrm{g} / \mathrm{m}^{3}$ in classrooms having natural ventilation or basic airconditioning [25]. Outdoor levels in this study ranged between $67.8 \mu \mathrm{g} / \mathrm{m}^{3}$ to $91.2 \mu \mathrm{g} / \mathrm{m}^{3}$. Indoor levels in the 6 Cities Study ranged between 8 and $28 \mu \mathrm{g} / \mathrm{m}^{3}$ with the authors suggesting a stratification of exposure levels.

The whole range of indoor $\mathrm{PM}_{2.5}$ levels obtained in this study was subdivided into three equal parts (tertiles) thus distinguishing between low exposure (lowest tertile) and high exposure to $\mathrm{PM}_{2.5}$ (highest tertile) [18]. $\mathrm{PM}_{2.5}$ exposure was assessed using pump-driven gravimetric filters, light scattering dust track monitors, and dispersion models $[15,18,25]$. Duration of data collection ranged from one day (school hours only) to five days (Monday-Friday) [18,25].

The association between indoor and outdoor $\mathrm{PM}_{2.5}$ concentrations and atopy in children was studied by Annesi-Maesano et al. $[18,28]$. High exposure to indoor $\mathrm{PM}_{2.5}$ levels was associated with an increased risk of exercise-induced wheezing [18]. Furthermore, fractional exhaled nitric oxide (FeNO) levels in both asthmatic and nonasthmatic pupils were higher in children exposed to $\mathrm{PM}_{2.5}$ levels above the third tertile (high exposure) [5]. In this study, Flamant-Hulin et al. described a $62 \%$ increase in FeNO among nonasthmatic pupils when exposed to high concentrations of indoor $\mathrm{PM}_{2.5}$ within the school environment [5].

Long-term exposure to $\mathrm{PM}_{2.5}$ levels exceeding 10 $\mu \mathrm{g} / \mathrm{m}^{3}$ in the school outdoor environment was directly associated with an increase in exerciseinduced wheezing and skin atopy among children [24,28].

\section{Limitations of Review}

Our review was limited by the selection bias and variation in methodologies in the studies. One major limitation was that individuals were exposed to different air qualities both in and out of the school environment. Martins et al. proposed the use of 'total exposure to air pollution,' which is made up of all different microenvironment exposures of the individual [9]. This model takes into account all the different potential individual exposures to pollutants by the persons being studied during a typical day of the person's life. When considering exposure to pollutants, more reliability studies are needed to quantify the impact of measured concentrations of pollutants on individual exposure [4]. This will help create accurate models that can predict the exposure of an individual to a whole range of pollutants.

\section{CONCLUSION}

Relatively little is known about school indoor air pollution. Furthermore, no studies were found for schools situated in small, densely populated island nations including Malta. Several studies have highlighted the presence of poor school indoor air quality with high levels of pollutants that are asso- 
ciated with respiratory diseases commonly found in atopic children. Unfortunately, little data exist about what remedial measures might reduce exposure to these pollutants with consequent improvement of students' symptoms. More research is needed to consolidate our knowledge about school indoor air quality and health to guide future interventions aimed at improving our children's well-being. Very few studies focus on the negative impact of poor school indoor air quality on teachers and school staff. The topic is particularly relevant for Malta, which has unique geographical and environmental characteristics making it difficult to extrapolate data obtained from other countries.

\section{REFERENCES}

[1] Makri A, Goveia M, Balbus J, Parkin R. Children's susceptibility to chemicals: a review by developmental stage. J Toxicol Environ Health 2004; 7: 417-35.

[2] Bennett W, Zeman K, Jarabek A. Nasal contribution to breathing and fine particle deposition in children versus adults. J Toxicol Environ Health 2008; A71: 227-37.

[3] Eder W, Ege M, von Mutius EJ. The asthma epidemic. N Engl J Med 2006; 355: 2226-35.

[4] Annesi-Maesano I, Baiz N, Banerjee S, Rudnai $\mathrm{P}$, Rive S, SINPHONIE Group. Indoor air quality and sources in schools and related health effects. J Toxicol Environ Health B Crit Rev 2013; 16: 491-550.

[5] Flamant-Hulin M, Caillaud D, Sacco P, PenardMorand C, Annesi-Maesano I. Air pollution and increased levels of fractional exhaled nitric oxide in children with no history of airway damage. J Toxicol Environ Health 2010; A73: 272-83.

[6] Shendell D, Prill G, Fisk R, Apte W, Blake M, Faulkner D. Associations between classroom $\mathrm{CO}_{2}$ concentrations and student attendance in Washington and Idaho. Indoor Air 2004; 14: 33341.

[7] Scarlett JF, Abbott KJ, Peacock JL, Strachan DP, Anderson HR. Acute effects of summer air pollution on respiratory function in primary school children in southern England. Thorax 1996; 51: 1109-14.

[8] Simoni M, Annesi-Maesano I, Sigsgaard T, et al. School air quality related to dry cough, rhinitis and nasal patency in children. Eur Respir J 2010; 35: 742-9.

[9] Martins P, Valente C, Papoila J, et al. Airways changes related to air pollution exposure in wheezing children. Eur Respir J 2012; 39: 24653.
[10] Zhao Z, Sebastian A, Larsson L, Wang Z, Zhang $Z$, Norback D. Asthmatic symptoms among pupils in relation to microbial dust exposure in schools in Taiyuan China. Pediatr Allergy Immunol 2008; 19: 455-65.

[11] Fraga S, Ramos E, Martins A, et al. Indoor air quality and respiratory symptoms in Porto schools. Rev Port Pneumol 2008; 14: 487-507.

[12] Mi YH, Norback D, Tao J, Mi L, Ferm M. Current asthma and respiratory symptoms among pupils in Shanghai, China: influence of building ventilation, nitrogen dioxide, ozone, and formaldehyde in classrooms. Indoor Air 2006; 16: 454-64.

[13] Mendell MJ, Heath GA. Do indoor pollutants and thermal conditions in schools influence student performance? A critical review of the literature. Indoor Air 2005; 15: 27-52.

[14] Castro HA, Cunha MF, Mendonca GA, Junger WL, Cunha-Cruz J. Effect of air pollution on lung function in schoolchildren in Rio de Janeiro Brazil. Rev Saude Publica 2009; 43: 26-34.

[15] Penard-Morand C, Raherison C, Charpin D, et al. Long-term exposure to close-proximity air pollution and asthma and allergies in urban children. Eur Respir J 2010; 36: 33-40.

[16] Norback D, Torgen M, Edling C. Volatile organic compounds, respirable dust, and personal factors related to prevalence and incidence of sick building syndrome in primary schools. $\mathrm{Br} \mathrm{J}$ Ind Med 1990; 47: 733-41.

[17] Smedje G, Norback D, Edling C. Asthma among secondary schoolchildren in relation to the school environment. Clin Exp Allergy 1997; 27: 1270-8.

[18] Annesi-Maesano I, Hulin M, Lavaud F, et al. Poor air quality in classrooms related to asthma and rhinitis in primary schoolchildren of the French 6 Cities Study. Thorax 2012; 67:682-8.

[19] Kim J, Elfman L, Mi Y, Johansson M, Smedje G, Norback D. Current asthma and respiratory symptoms among pupils in relation to dietary factors and allergens in the school environment. Indoor Air 2005; 15: 170-82.

[20] Smedje G, Norback D. Incidence of asthma diagnosis and self-reported allergy in relation to the school environment--a four-year follow-up study in schoolchildren. Int $\mathrm{J}$ Tuberc Lung Dis 2001; 5: 1059-66.

[21] Marks GB, Ezz W, Aust N, et al. Respiratory health effects of exposure to low-NOx unflued gas heaters in the classroom: a double-blind, cluster-randomized, crossover study. Environ Health Persp 2010; 118: 1476-82.

[22] Walinder R, Norback D, Wieslander G, Smedje $\mathrm{G}$, Erwall C. Nasal congestion in relation to low air exchange rate in schools. Evaluation by 
acoustic rhinometry. Acta Otolaryngol 1997; 117: 724-7.

[23] Norback D, Walinder R, Wieslander G, Smedje $G$, Erwall $C$, Venge $P$. Indoor air pollutants in schools: nasal patency and biomarkers in nasal lavage. Allergy 2000; 55: 163-70.

[24] World Health Organization. WHO Guidelines for Indoor Air Quality: Selected pollutants [Book on the internet]. WHO Regional Office for Europe. 2010; [cited 2014 Oct 8]. Available from: http://www.euro.who.int/ data/assets/pdf file/00 09/128169/e94535.pdf

[25] Zuraimi M, Tham SK, Chew FT, Ooi PL. The effect of ventilation strategies of child care centers on indoor air quality and respiratory health of children in Singapore. Indoor Air 2007; 17: 31727.

[26] Chen PC, Lai CC, Chan JS, Hwang JS, Yang CY, Wang JD. Short-Term effect of ozone on the pulmonary function of children in primary school. Environ Health Persp 1999; 107: 921-5.

[27] Romieu I, Lugo MC, Velasco SR, Sanchez S, Meneses F, Hernandez M. Air pollution and school absenteeism among children in Mexico City. Am J Epidemiol 1992; 136: 1524-31.

[28] Annesi-Maesano I, Moreau D, Caillaud D, et al. Residential proximity fine particles related to allergic sensitisation and asthma in primary school children. Respir Med 2007; 101:1721-9.

[29] Csobod E, Rudnai P, Vaskovi E. School Environment and Respiratory Health of Children (Search) [Book on the internet]. Hungary: The Regional Environmental Center for Central and Eastern Europe Country Office; 2010 [cited 2014 Oct 7]: Available from: http://www.isprambiente.gov.it/files/progetti/searc h-results-europe-rec.pdf

[30] Graveland H,Van Roosbroeck SA, Rensen WM, Brunekreef B, Gehring U. Air pollution and exhaled nitric oxide in Dutch schoolchildren. Occup Environ Med 2011; 68: 551-6.

[31] Milligan PJ, Brabin YJ, Kelly MG, et al. Association of spatial distribution of childhood respiratory morbidity with environmental dust pollution. J Toxicol Environ Health A 1998; 55: 169-84. 